\title{
Techniques for the Growth of Large Single Crystals of Potassium of High Purity *
}

\author{
Howard J. Foster ${ }^{1}$ \\ Institute for Materials Research, National Bureau of Standards, Washington, D.C. 20234 \\ and \\ Paul H. E. Meijer ${ }^{2}$ \\ Institute for Basic Standards, National Bureau of Standards, Washington, D.C. 20234
}

(December 5, 1966)

\begin{abstract}
The preparation of large, high purity, single crystals of potassium is described. First, high initial purity is obtained by careful zone refining. Then, a modification of the Bridgman technique is applied which leads to crystals with resistivity ratios up to 6800 at $4.2^{\circ} \mathrm{K}$. The modification consisted of a heat shield as described in the test. We concluded from the magnetoacoustic experiments that were subsequently done with these samples, that the samples had mean free paths of the order of $10^{-2} \mathrm{~cm}$. Typical crystals were $7 / 8$ in diam and about 8 in long, with growth direction along [110]. A description is given of an easy method of orientation as well as the use of a spark erosion technique to cut and polish the surfaces.
\end{abstract}

Key Words: Crystal growth, fermi surface, orientation, potassium, spark cutting, zone refining.

\section{Introduction}

The unavailability of large crystals of the alkali metals on a commercial basis and the lack of knowhow in the laboratory for preparing and handling these highly reactive metals of adequate size and purity continue to be the chief reasons for the limited amount of experimental data on the properties of these metals. Their unique and simple electronic and crystal structures have always made them attractive from a theoretical point of view. As a consequence, one finds in the literature that the experimental studies have tended to lag behind the tremendous amount of theoretical work on the alkalies. This, in turn, has stimulated some interest in the development and/or the refinement of existing techniques for preparing the alkali metals for various types of experimental studies.

In the last few years there have been some reports of progress in establishing techniques for preparing single crystal specimens of some of the alkali metals. Among these are the techniques described by Daniels $[1]^{3}$ for sodium. Later, Grimes [2] gave a description of techniques that he used in the preparation of the alkali metals, sodium and potassium, for cyclotron resonance studies. More recently, Hoyte and Miel.

\footnotetext{
*Supported in part by the U.S. AEC, Grant No. AT(40-1)-2861, Based on portion of thesis submitted in partial fulfillment of the requirements for the $\mathrm{Ph}$. D. degree to the thesis submitted in partial fulfillment of the requirements for the Ph. D.
Department of Physics, the Catholic University of America, Washington, D.C.

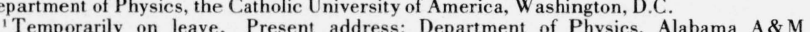
'Temporarily on leave. Present
College, Normal, Alabama 35762 .

${ }^{2}$ Also with Catholic University of America, 620 Michigan Ave., NE., Washington, D.C. 20017.

${ }^{3}$ Figures in brackets indicate the literature references at the end of this paper.
}

czarek [3] published a paper on the growth of large single crystals of potassium; however there is no evidence in their paper of the level of purity obtained. In the above references, as in the present paper, the methods have much in common, especially in regard to the technique of crystal growth, i.e., via the Bridgman technique. The main difference in the present work is the introduction of a heat shield, which prevented the premature solidification of the top of the melt.

The crystals grown by this method were subsequently used to measure the magnetoacoustic absorption in order to determine the Fermi surface of potassium [4]. From the result of these measurements it was concluded that the mean free path is about $10^{-2} \mathrm{~cm}$. The same samples were used in an attempt to defect the Overhauser spin density waves [5] and measurements of the resistivity ratio (at Brown University) gave values of 6800 and lower [6].

We feel that the good quality of the crystals obtained is due to the fact that they were both zone refined, to reduce the "chemical" impurities as much as possible, and carefully grown, to reduce the dislocations and other mechanical imperfections to a minimum. The heat shield prevents the reentry of impurities in the higher layers of the boule, and assures that they will arrive at the top where they can be easily removed.

\section{Crystal Growth of Potassium}

Despite the fact that the potassium as received from the MSA Research Corporation, Callery, Pa,, was reportedly of the order of 99.97 percent purity, we 
found, contrary to reference 3 , that it is necessary to zone-refine the material beforehand. The theoretical and practical aspects of nucleation and crystal growth from the melt have been adequately described by Holmes [7], Tiller [8], Goss [9], and others. The zonerefined metal was subjected to a modified version of the Bridgman technique to grow single crystals under paraffin oil in a stainless steel crucible in the atmosphere. With this method, solidification of the crystalline phase from its melt is initiated in a sharply pointed tip at the lower end of the crucible, under proper temperature conditions. The phase transformation is continuously driven by the controlled extraction of heat through the initially formed crystal seed in the nucleation tip throughout the growth process.

The detachable two piece stainless steel crucible ( $7 / 8$ in ID and about 9 in overall length) is illustrated in figure 1 . The upper portion is wound with about 70 turns of asbestos-covered nichrome wire (B \& S \#20), arranged in gradient fashion over all but about $1 / 4$ in of each end of the cylinder, from six turns per inch near the bottom to adjacent turns for the last $1 \frac{1}{2}$ in near the top. This portion is thermally insulated with a preparation of high temperature cement, in order to insure increased electrícal heating efficiency and minimum heat loss through the crucible wall during the growth of the potassium single crystals. An a-c voltage for supplying electrical current through the variable turns of heater wire was used to establish and maintain a vertical temperature gradient $\frac{\Delta T}{\Delta Z}$ through the molten boule. The bottom detachable

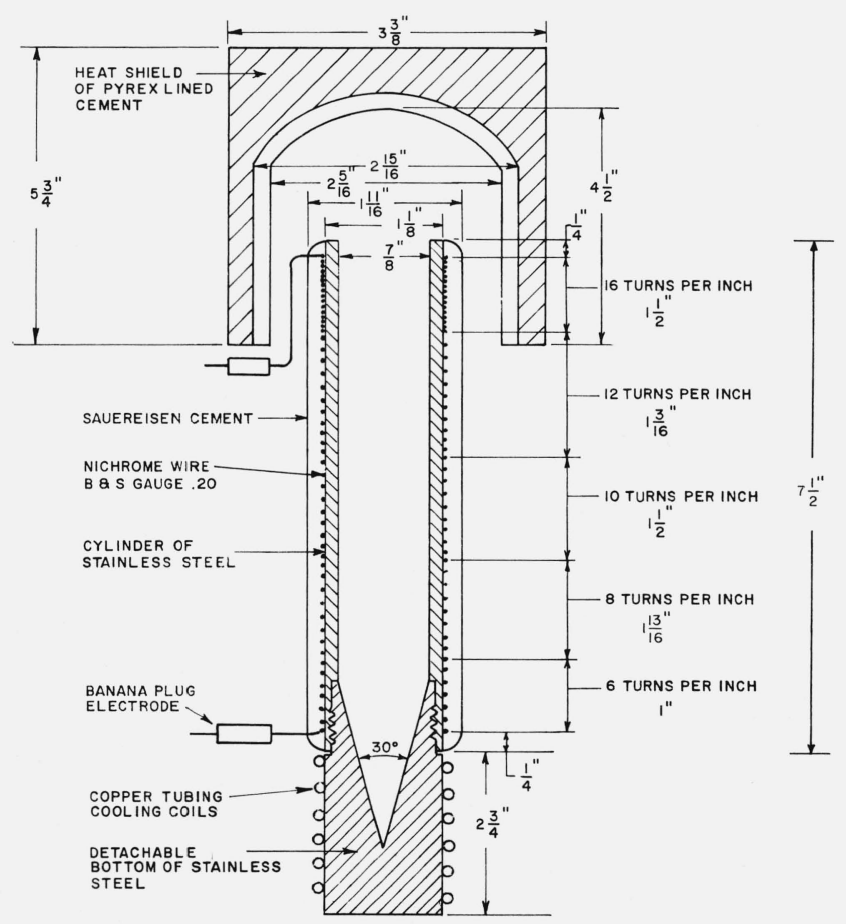

FIGURE 1. Bridgman crucible and heat shield arrangement for growing the potassium crystals in oil. portion of the crucible, equipped with cooling coils of copper tubing, provided the proper undercooling conditions for directed heat extraction and crystal growth from the nucleation tip.

The crucible as described above provided a temperature gradient in the molten potassium boule of about $4.24{ }^{\circ} \mathrm{C}$ per inch at $20 \mathrm{~V}$ input, without undercooling at the bottom. This corresponded to a temperature of the potassium in the nucleation tip of about $64{ }^{\circ} \mathrm{C}$, i.e., slightly above the solidification point of $63.7{ }^{\circ} \mathrm{C}$, while the top region of this $8 \frac{1}{2}$ in molten boule was at a temperature of about $100^{\circ} \mathrm{C}$. At an input heater voltage of $12 \mathrm{~V}$ or less the $8 \frac{1 / 2}{}$ in potassium boule became completely solid. It was, therefore, only necessary to establish the rate of voltage reduction from 20 to $12 \mathrm{~V}$ heater input, with proper undercooling, for growth of the molten boule into a large single crystal of potassium. The design of the electrical circuitry for reducing the heater current, while simultaneously extracting heat through the nucleation tip of the boule, was arrived at by trial and error, with some guidance from published data on metal crystal growth rates [8,9]. For the crucible design as described above, the rate of crystal growth $R$ of potassium from its melt was estimated at about 1 in per hour, i.e., $\mathrm{R}=7 \times 10^{-4}$ $\mathrm{cm} / \mathrm{sec}$. The manually operated and motor driven variacs, incorporated in the electrical circuitry, provided for constant power input to the heater windings, as well as for automatic increase and/or reduction in the heater power, in the voltage range from 0 to $6 \mathrm{~V}$ per hour, as desired. A voltage reduction rate of $1 \mathrm{~V}$ per hour, simultaneously with undercooling at the bottom of the crucible, achieved the specified rate of growth of the potassium single crystal. A heat shield surrounding the top 3 in portion of the crucible was used to prevent the formation of "rogue" crystals due to premature solidification of the melt ahead of the advancing solid-liquid interface, near the top of the potassium boule. A plot of the motion of the freezing interface (approximately) with time, under the voltage reduction and cooling conditions for growing the potassium single crystals, is shown in figure 2. It is clear from this figure that without the heat shield the growth rate starts to increase rapidly near the top.

The experimental procedure for growing the potassium crystals was as follows. The zone refined ingots with their impure ends discarded were placed in the crucible, which was coated with paraffin oil to avoid sticking, and tamped with a steel rod to achieve a continuous solid boule. The top of the solid boule, within about $3 / 4$ in of the top of the crucible, was then covered with paraffin oil and the manually driven variac adjusted to an input heating voltage of $30 \mathrm{~V}$. This corresponded to temperatures of about 130 and $100{ }^{\circ} \mathrm{C}$ at the top and bottom regions of the molten boule, respectively. Entrapped gases in the metal and oil, during the initial heating period of about $2 \mathrm{hr}$, were removed by vibration upon striking the crucible at the bottom. Sometimes it was necessary to cool, remove, etch (with a solution of 1:50= sec-butyl alcohol:xylene), and repeat the process for 4 or 5 times before achieving a smooth and solid potassium boule. 


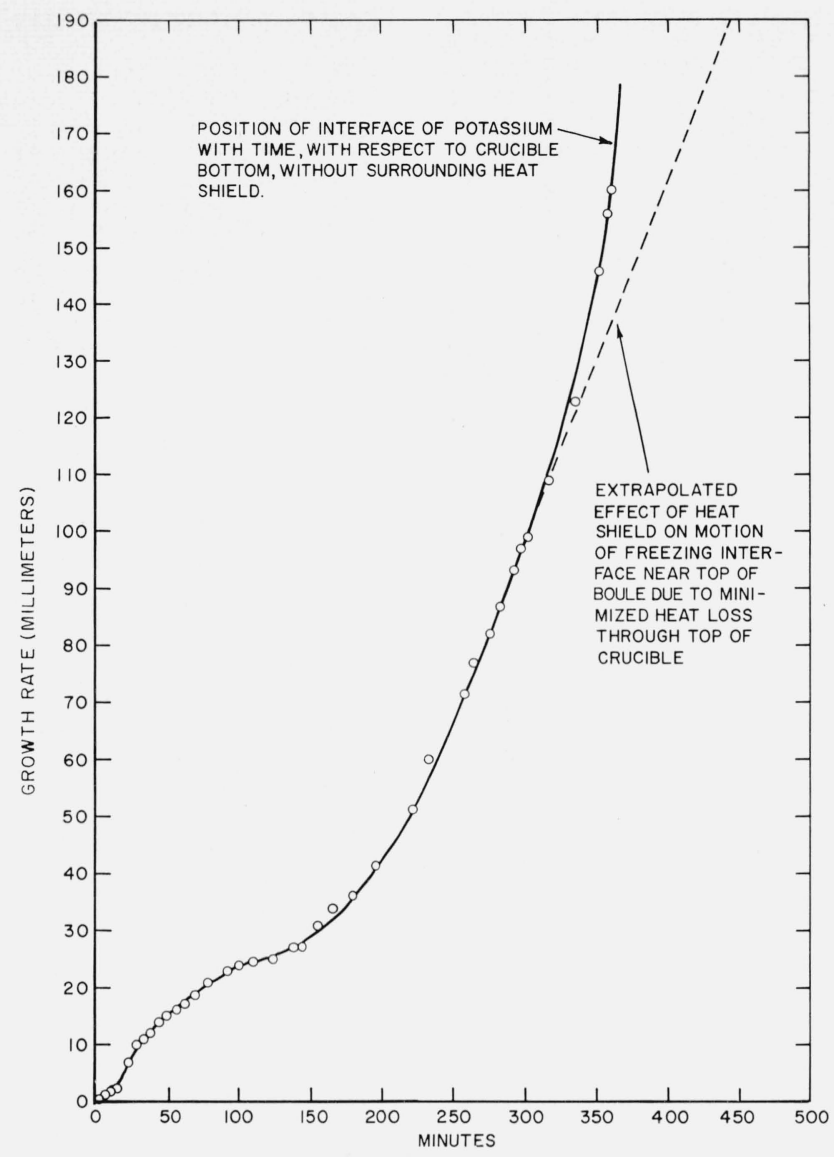

Figure 2. Potassium crystal growth rate plot (approximate).

Once this was done, the boule was melted and allowed to "cook" for several hours, usually overnight, at $20 \mathrm{~V}$ heater input, corresponding to a temperature just above the solidification point of the potassium melt in the nucleation tip. With the heat shield in place, a continuous and steady flow of nitrogen gas, cooled in a bath of liquid nitrogen or dry-ice slush and adjusted to a predetermined rate from a calibration run, was passed through the cooling coils on the bottom portion of the crucible. At this point, the motor for driving the variac was actuated to reduce the heater voltage from $20 \mathrm{~V}$ at a rate of $1 \mathrm{~V}$ per hour. The crystal growth process, with the prescribed growth rate of $7 \times 10^{-4} \mathrm{~cm} / \mathrm{sec}$ or about $1 \mathrm{in} / \mathrm{hr}$, was uninterrupted for a period of about $9 \mathrm{hr}$ to insure complete solidification of the boule. The resulting single crystal potassium boule, 0.875 in in diameter and 7 to 8 in long, was then allowed to cool further to room temperature before removal from the crucible with a plunger. The large single crystals of potassium were subsequently etched as previously described and then stored in paraffin oil.

The polycrystalline top of the otherwise single crystal potassium boule in figure 3 , is typical of the case of premature solidification ahead of the advancing solid-liquid interface, grown without the use of the heat shield. Single crystal potassium boules in

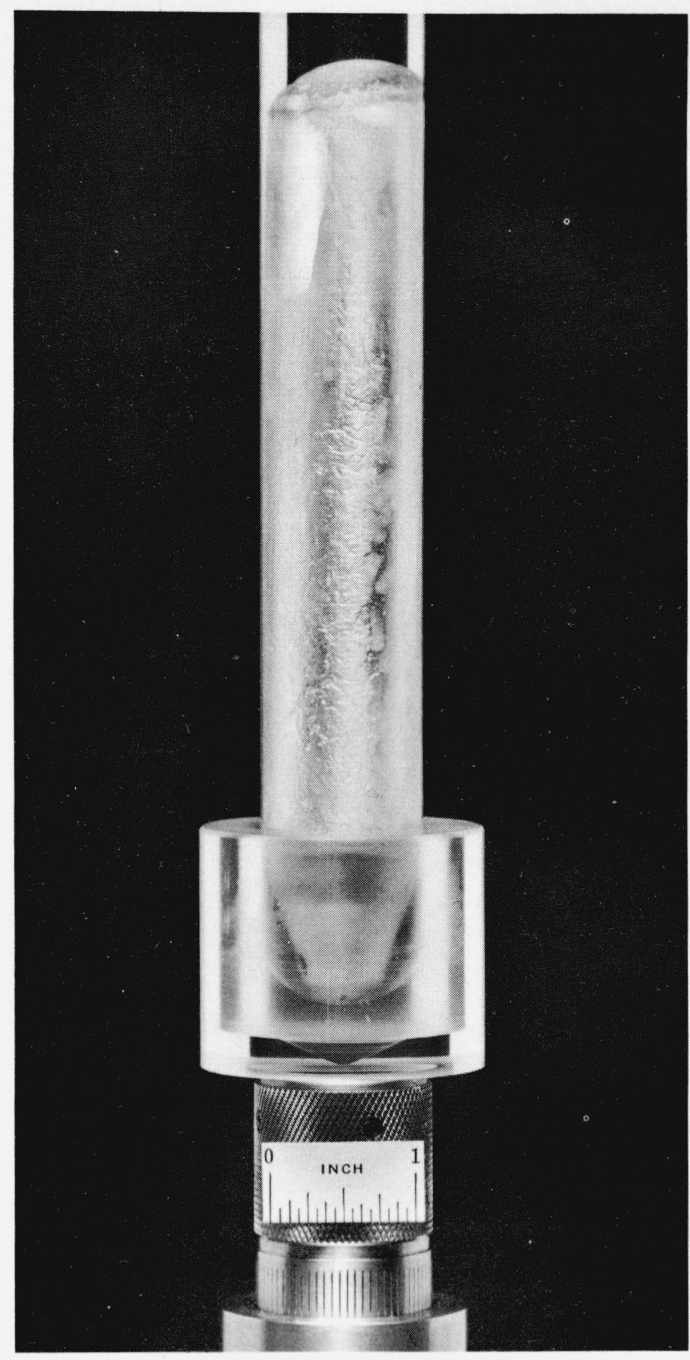

Figure 3. Potassium crystal grown without the use of heat shield, resulting in the formation of a polycrystalline region near top of boule.

oil, all showing highly reflecting blaze planes are , shown in figures $4,5 \mathrm{a}$, and $5 \mathrm{~b}$. The blaze planes are characterized in each of the crystals by bright reflections of light from narrow strips of the cylindrical surface along the entire length of the boule. The single crystal potassium boules, displayed in the photographs in figures 4 and 5 were positioned to show one of the peripheral blazes of light along the boule. Photographs shown in figure 5 ( $\mathrm{a}$ and $\mathrm{b}$ ) are of the same crystal boule in paraffin oil, photographed within $30 \mathrm{~min}$ (a) and after $12 \mathrm{hr}$ (b) after etching. These photographs illustrate that a reaction occurs in spite of the precautions taken to protect the surface. The comparatively high reflectivity along certain peripheral positions of the crystal is due to preferential etching in these crystallographic directions. The brightest planes in these crystals (determined by methods to be described later), were found to coincide with $\langle 111\rangle$ directions in the bcc potassium lattice. 


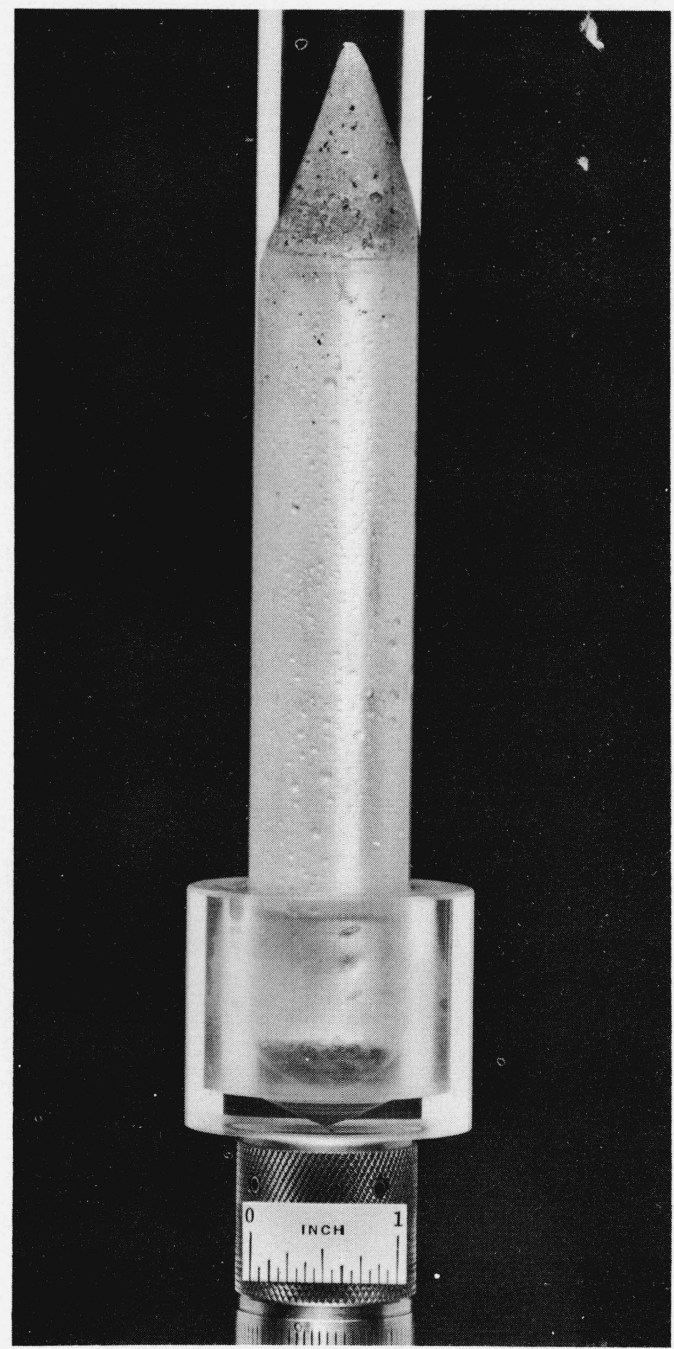

Figure 4. Potassium single crystal positioned to show one of the four visible blaze planes having $\langle 111\rangle$ directions along the boule.

\section{Orientation and Cutting of the Potassium Single Crystals}

Because of the complementary aspects of the orientation and cutting techniques used in the preparation of the potassium single crystal specimens, they are both presented in this section.

The potassium single crystal boules, purified and grown by the techniques described above, were first oriented optically before being cut into specimens by a spark erosion technique. Transmission $\mathrm{x}$-ray diffraction studies of thin samples of these crystals were used to confirm the accuracy of the optical method which provided a rapid method of orientation. They also confirmed that the direction of growth was indeed in the [110]-direction. The optical method of orienting the potassium crystals also proved to be reliable and much more convenient than the $x$-ray technique.

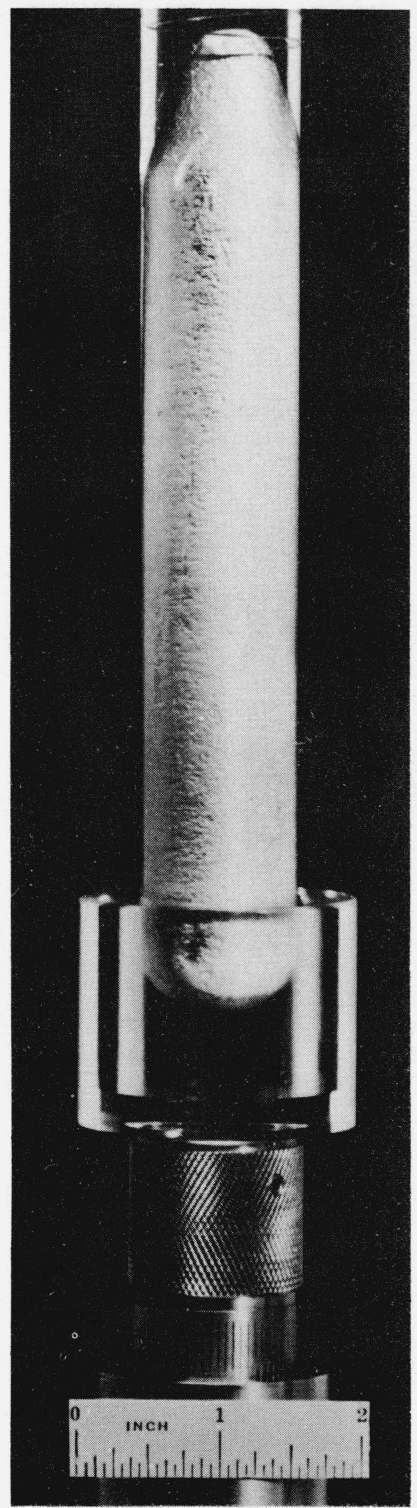

(a)

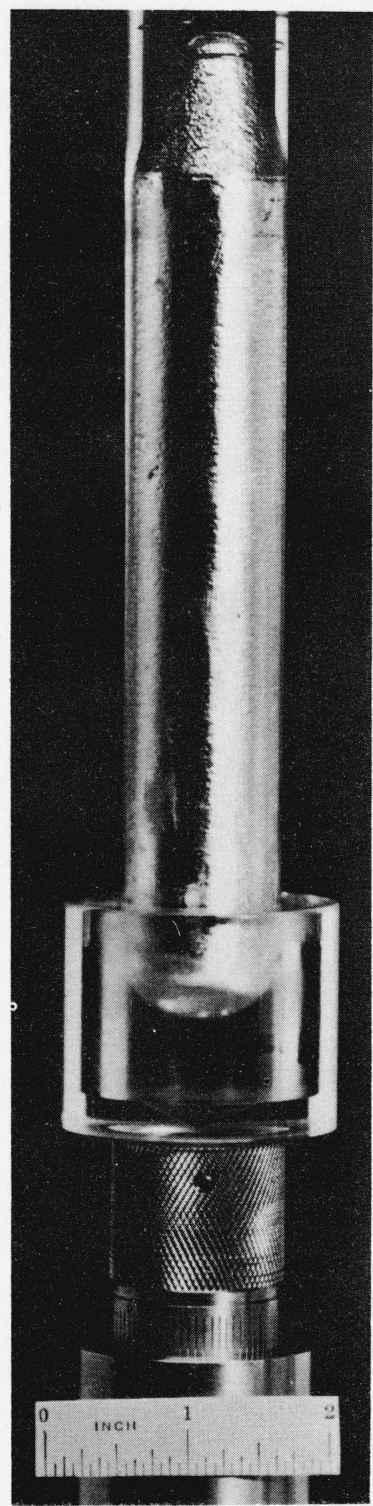

(b)
Figure 5. An illustration of the effect of time after etching on the appearance of one of four $\langle 111\rangle$ blaze planes displayed along the periphery of the same single crystal potassium boule in oil; photographed (a) within $1 / 2 \mathrm{hr}$ after etching, and (b) about $12 \mathrm{hr}$ after etching.

Preferential etching of the potassium single crystal boules in a solution of 1 part sec-butyl alcohol and 50 parts xylene, and allowing the boule to remain in paraffin oil for an hour or more, produced blaze planes of sufficient brightness to specify the orientation of the crystal. The angles between the peripheral blaze planes were determined by rotating the uncut single crystal potassium in oil and measuring the angles in degrees between successive blazes of light from the boule. The simple requirements of the method consisted of a rotating jig, calibrated in degrees, with provisions for supporting and rotating the uncut crystal in a vertical glass tube under paraffin oil, a 
small projection lamp, and a telescope for observing the intense blazes of light along the boule as the crystal was rotated. The optical arrangement is shown in figure 6 . The relative angular positions of the blaze planes from each of the potassium crystals grown and observed within $2 \mathrm{hr}$ after removal from the etch were $0,70,180$, and $250^{\circ}$. From this, the angles between the 4 successive reflecting planes were determined to be $0,70,110$, and $70^{\circ}$, with an accuracy of $\pm 2^{\circ}$ The two-fold rotational symmetry of the peripheral blazes of light suggested that the crystal growth direction was [110] and that the highly reflecting blaze planes were all $\langle 111\rangle$, perpendicular to the crystal growth axis. Note that the measured angular positions of the blaze planes about the periphery of the potassium are in agreement with the $\langle 111\rangle$ directions $\left(0,70.53,109.47\right.$, and $70.53^{\circ}$ which lies in the (110) plane. In addition to the strong $\langle 111\rangle$ blazes, low intensity [110] directions were observed about the periphery of a single crystal potassium boule after being stored in paraffin oil for a month. These findings are not in disagreement with the observations of Grimes [2] who used a different etch and observed the brightest blaze to be $\langle 110\rangle$. A projection of the $\langle 110\rangle$ plane (growth direction) showing the per-

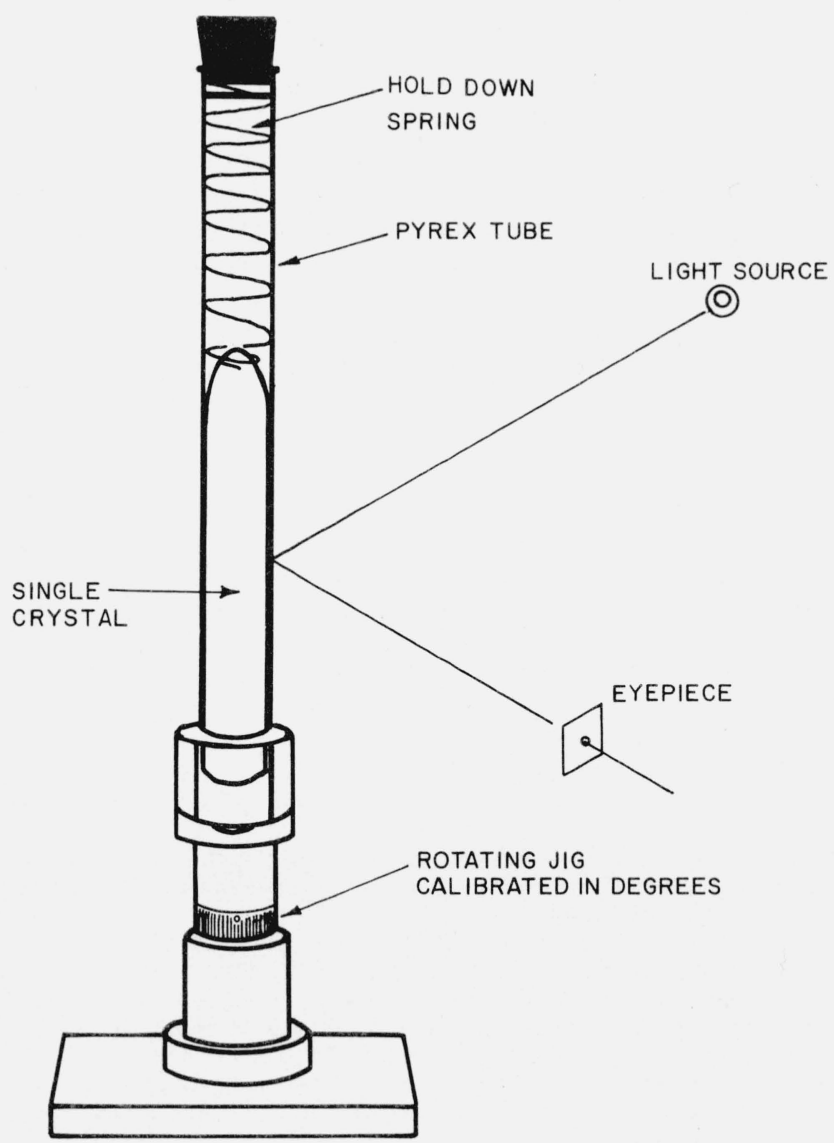

FIGURE 6. Schematic arrangement of the optics and the crystal boule in oil mounted in a coaxial rotating jig for locating the angular positions at which maximum light reflections (blaze planes), occur. pendicular directions of the high symmetry blaze planes observed in potassium is shown in figure 7 . The brightest $\langle 111\rangle$ blaze planes also served as convenient markers for specifying the transverse magnetic field directions in the crystal, for the ultrasonic attenuation studies [4].

Transmission x-ray diffraction studies of thin wafers of the cylindrical boule and peripheral sections in the directions of the bright blazes perpendicular to the growth axis confirmed the optical findings. The thin samples less than $1 / 8$ in thick for the $x$-ray studies were cut by a spark erosion technique to be described later. The x-ray specimens were etched, as described above, followed by coating with a thick solution of vaseline and paraffin oil for the protection of the potassium crystal in the atmosphere while mounted in the goniometer for long $\mathrm{x}$-ray exposures $\left(1 \frac{1 / 2}{\mathrm{hr}}\right)$. Fear of the effect of the vaseline coating on the displayed diffraction patterns was removed by comparative x-ray diffraction patterns of single crystal quartz, with and without the vaseline coating. No effect of the vaseline coating on the diffraction pattern of quartz was observed.

A spark erosion machine, generally used for precision machining of hard metals, was used to cut the potassium single crystals. The essential features of the spark erosion or arc cutting machine are (1) the servo driven vibrating head with a chuck for supporting and controlling the vertical motion of the arcing electrode; (2) the precision mounted table below the head with two degrees of freedom for accurate positioning of the samples with respect to the electrode for cutting the desired specimen shapes with parallel surfaces; (3) the transparent enclosure of the precision

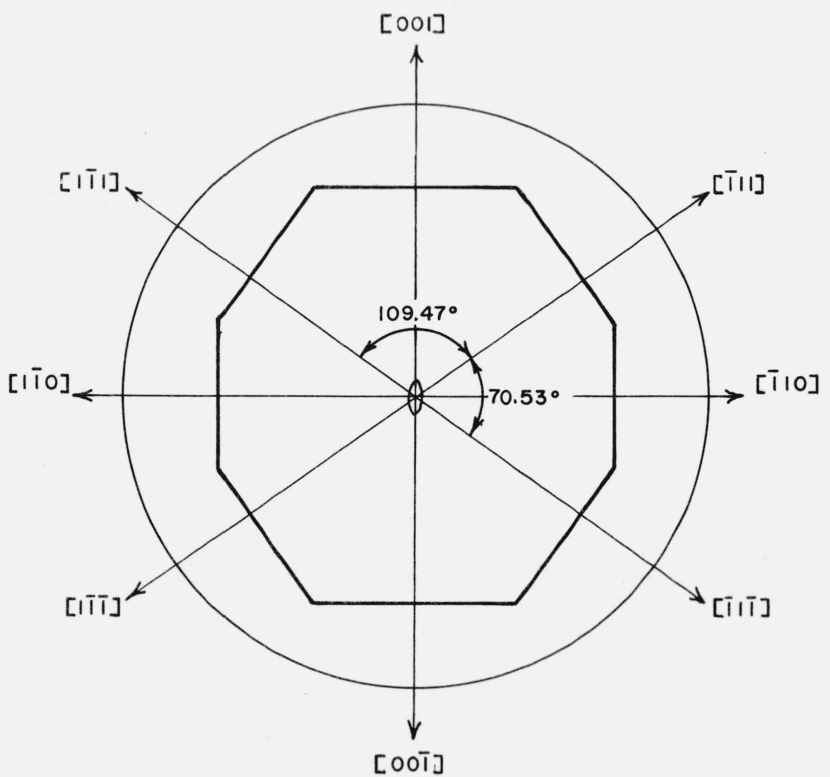

FIGURE 7. Angular positions and the identification of peripheral blaze planes in potassium after etching, in agreement with the $[110]$ growth axis projection.

The $\langle 111\rangle$ 's blaze brightest, the $\langle 110\rangle$ 's and $\langle 100\rangle$ 's blaze with lower intensity. 


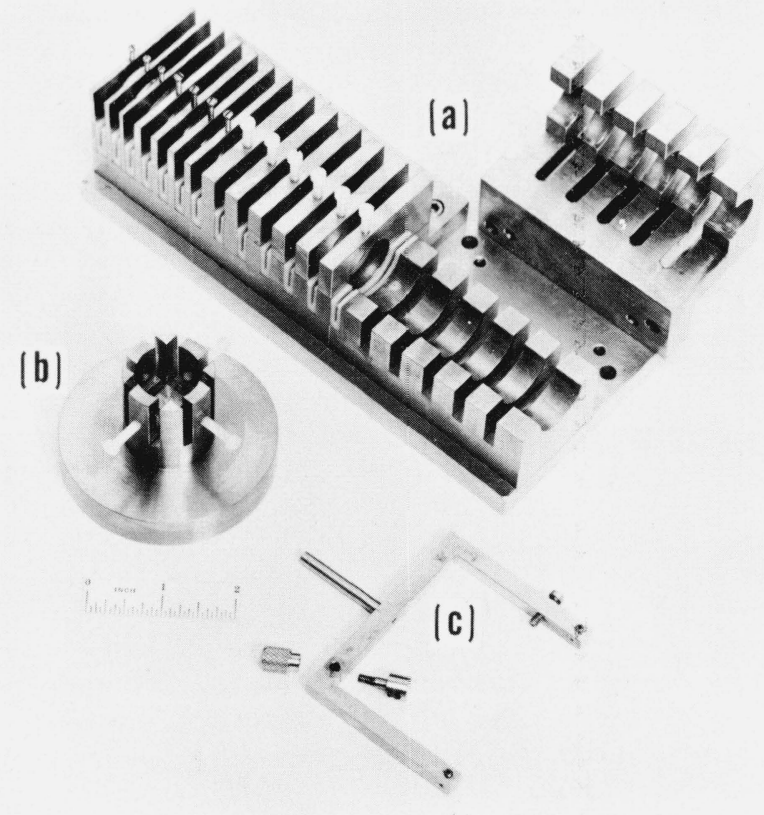

FIGURE 8. Sample holders $(a)$ and $(b)$ and the electrode and support (c) used for cutting the potassium single crystals by a spark erosion technique.

table for observation of the arc cutting process in the recirculating dielectric fluid; and (4) the electrical power supply for automatic operation over a wide range of arcing characteristics and cutting speeds to achieve the desired finish of the arc cut surface.

The two sample holders (a) and (b) of stainless steel and brass and the electrode of 0.004 in steel wire mounted in its support (c) are shown in figure 8 . The larger sample holder (a) with slotted and removable sections was used to cut cylindrical samples from the single crystal potassium boule. These samples were less than $1 / 8$ in thick for $x$-ray diffraction studies of the growth direction and about $1 / 2$ in to $5 / 8$ in thick for the ultrasonic studies. The smaller sample holder (b) was used to cut, from short cylindrical lengths of the crystal boule, thin peripheral sections in the direction of the blaze planes for x-ray diffraction studies. A set of instrument operating characteristics for smooth and flat cuts of the potassium crystals, such as the spark gap voltage and current, the feed speed of the chuck mounted electrode in the head, and amplitude of the electrode oscillator, were chosen by trial and error.

The potassium boules or shorter samples were secured in the appropriate holder and mounted on the precision table under the recirculating dielectric fluid. The head with the mounted electrode was lowered by manual control for precision positioning of the wire electrode with respect to the sample and then lowered further to start the arcing process upon electrical contact with the sample. At this point, automatic operation was switched in. A jet of the dielectric fluid was continuously direeted at the arc gap in order to achieve smooth crystal surfaces by removing the reaction products of the spark erosion process. The dielectric fluid, sangajol or terapine generally used with this machine, had no damaging effect on the potassium single crystals. The arc cutting method eliminated the necessity for any mechanical polishing of the potassium specimens to achieve smooth, parallel, and flat terminal surfaces of the crystals for the ultrasonic studies. When desired, polishing was achieved by slow passage of the arcing electrode within 0.005 in of the previously arc cut rough surface. The arc cutting method was also less time consuming than the string saw and mechanical polishing techniques generally used for preparing the single crystal specimens of potassium. For example, a spark gap voltage of $75 \mathrm{~V}$ dc, with low settings of the other operating characteristics of the spark erosion machine, produced a cut through the boule in about $10 \mathrm{~min}$. The resulting arc cut terminal surfaces of the potassium single crystal specimens for the ultrasonic attenuation studies at liquid helium temperatures were of a mat finish, flat and parallel, which bonded very well to the transmitting and receiving transducers, using high viscosity $(60,000 \mathrm{cs})$ Dow Corning \#510 oil as the bonding agent.

\section{Summary}

It is intended that the techniques described in this paper will go a long way toward eliminating the trialand-error approach in the preparation of large and pure single crystal specimens of the alkali metal, potassium, for various kinds of experimental studies. It is also worth noting that similar methods presented in this work may be applicable in the preparation of single crystals of the other alkali metals, all of which have very similar physical and chemical properties.

The authors thank Edward A. Stern of the Department of Physics and Astronomy, University of Maryland, for his kind permission to use their spark erosion machine for cutting the potassium crystal specimens.

\section{References}

[1] W. B. Daniels, Phys. Rev. 119, 1246 (1960).

[2] C. C. Grimes, Ph.D. thesis, University of California, 1962 (unpublished).

[3] A. F. Hoyte and E. V. Mielczarek, Appl. Mater. Res. 4, 121 (1965).

[4] H. J. Foster, P. H. E. Meijer, and E. V. Mielczarek, Phys. Rev. 139, A1849 (1965).

[5] M. Greene, A. Hoffman, A. Houghton, R. Peverley, J. Quinn and G. Seidel, Physics Letters 21, 135 (1966).

[6] We are indebted to Mr. Hoffman for these values. Some crystals were poorer, but this is probably due to aging.

[7] P. J. Holmes, J. Phys. Chem. Solids 24, 1239 (1963).

[8] W. A. Tiller, The Art and Science of Growing Crystals, p. 276 , edited by J. J. Gilman (John Wiley \& Sons, Inc., New York, N.Y., 1963).

[9] A. J. Goss, The Art and Science of Growing Crystals, p. 314, edited by J. J. Gilman (John Wiley \& Sons, Inc., New York, N.Y., 1963).

(Paper 71C2-443) 